\title{
Faculty members in conflict with president of Japanese university
}

\author{
Allegations over research results highlight the difficulties of investigating \\ high-ranking administrators.
}

\section{BY DAVID CYRANOSKI}

$\mathrm{T}$ ension has been high at one of Japan's top research universities. A number of faculty members at Tohoku University in Sendai have called for a fuller investigation into four papers by the university's president, materials scientist Akihisa Inoue, and have expressed dissatisfaction with the university's handling of the matter. There is no reason to conclude that there was any kind of manipulation of data by Inoue, and the accusations over his work are unproven. However, the spat underscores the challenges involved when a university investigates one of its own - especially when the individual under scrutiny is the university's president - as well highlighting the difficulty of verifying experimental results that require extreme precision.

The controversy has been simmering for more than three years, during which critics have repeatedly questioned the results of the four papers ${ }^{1-4}$ by Inoue. An internal committee at the university assessed the criticisms and ruled that a formal investigation was not warranted. In the committee's December 2007 report, senior officials questioned whether the criticism was motivated by "malice" and "divorced from a pure concern for academic development". Since then, university faculty members have repeated the criticisms and raised others. But Inoue, a prolific specialist in an unusual form of alloy called metallic glasses, told Nature that his team has unique skills and experience in producing the alloys, which could explain why other scientists have failed to reproduce some of his lab's results.

Collaborators, competitors and critics all recognize Inoue as a pioneer. One colleague says his contribution to the science of bulk metallic glasses is "legion". In 2009, Inoue and William Johnson, of the California Institute of Technology in Pasadena, shared the American Physical Society's prestigious James C. McGroddy Prize for New Materials for their work in the field.

Metallic glasses are formed by cooling a molten alloy so quickly that it doesn't have time to crystallize. This leaves its atoms in a state of disorder - disrupting the regular crystalline structure seen in normal metal alloys. The resulting materials are stronger, more elastic and more resistant to corrosion.

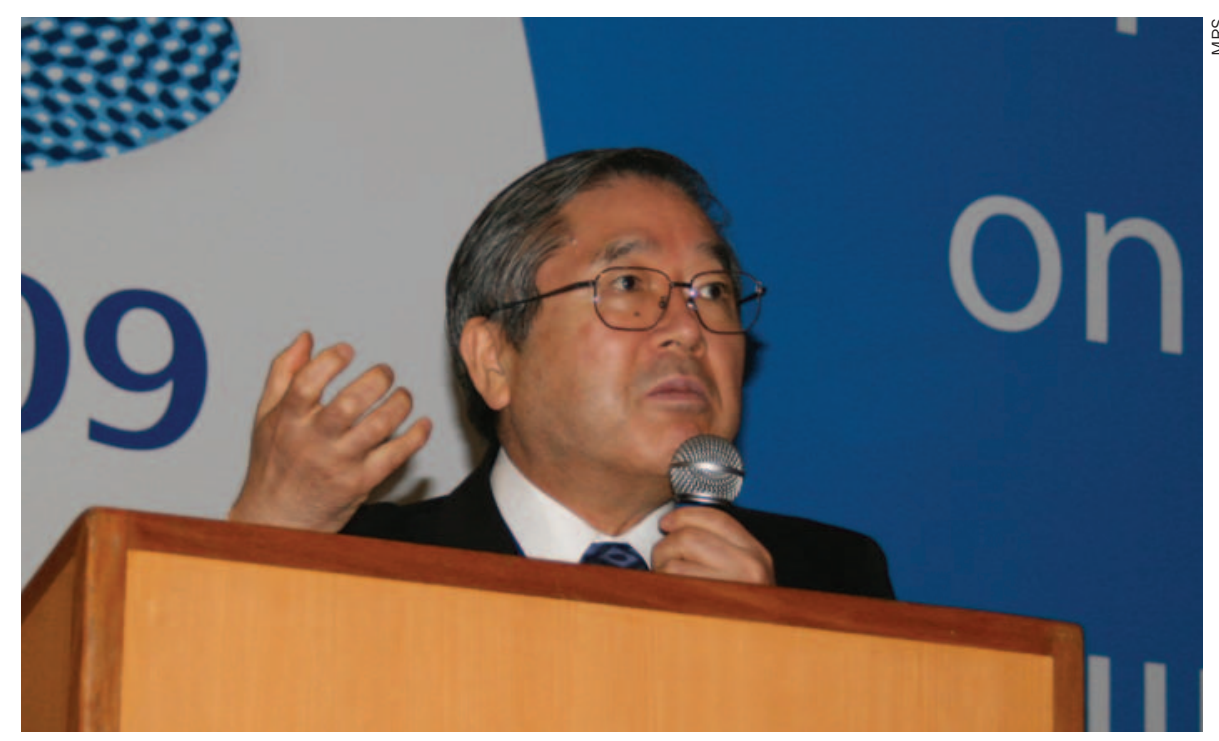

Akihisa Inoue is a leading researcher in bulk metallic glass alloys.

Although broad commercial applications have yet to take off, partly because of the need for novel processing methods, scientists are starting to take advantage of the materials' unique properties to make golf clubs, mobile-phone casings and biomedical devices ${ }^{5,6}$. "It is one of the most important areas in materials science from a basic scientific point of view, as well as for application-driven developments," says Hans-Jörg Fecht, a materials scientist at Ulm University in Germany.

Inoue has published more than 2,500 articles since 1973. He and his group have reported making numerous glassy alloys and producing samples much thicker than those reported by other groups.

\section{QUESTIONS RAISED}

But in May 2007, a series of anonymous letters began arriving at Tohoku University and other places alleging that the four papers ${ }^{1-4}$ co-authored by Inoue in the 1990s contained inconsistencies in the way that the data were presented. The letters also alleged that others in the field had been unable to reproduce the results.

In response to these allegations, Tetsuo Shoji, the university's executive vice-president for research affairs at the time, formed a five-person committee to decide whether a full-scale investigation was warranted. In December
2007, the committee issued a 12-page report that said there were "no rational grounds" for a full investigation. On the problem of irreproducibility, the report said: "various factors including the purity of materials ... the cooling method, the protocols, temperature control, moisture control and time control can bring about differences in results, making it easy to imagine how problems in reproducing work might exist among researchers."

Nine metallic-glass experts outside Japan contacted by Nature generally lauded Inoue's contribution to the field. At least one, however, had specifically tried to produce some of the metallic glasses described in the papers ${ }^{1-4}$ under discussion but had failed to achieve the large dimensions reported by Inoue. Two others were unable to reproduce other metallicglass results from Inoue's laboratory.

Inoue disagrees that any difficulties experienced by other groups trying to reproduce his experiments mean that his work is problematic. "We are far ahead of other groups," he says. "If they have the proper level of technological know-how, they should be able to reproduce the work." He adds that his work has been independently reproduced by other groups, although the examples he cites ${ }^{7-10}$ involve significantly smaller sample diameters or glasses of a different composition from those in the four 1990s papers. 
Inoue also refers to a paper ${ }^{11}$ that his group published in 2007 as evidence that the earlier results can be reproduced. This paper reported the production of a zirconium-based metallic glass rod 30 millimetres in diameter. Tsuyoshi Kajitani, a researcher at Tohoku University, has questioned whether the evidence provided in the 2007 paper proved the glassy nature of the sample ${ }^{12}$, but Inoue and his co-authors stand by the paper, and Inoue has defended it in writing $^{13}$. Moreover, in response to queries from Nature, Alain Yavari, a director of research at the CNRS in France, says that X-ray microprofiling tests run at the European Synchrotron Radiation Facility in Grenoble as part of another experiment show that a 30-millimetrethick sample of the zirconium-based material received from Inoue was indeed glassy, supporting the results of the 2007 paper.

Resolution of the broader dispute has been complicated by the fact that Inoue's co-author Tao Zhang has been unable to produce the original laboratory notebooks or glass samples from the experiments that they did for the four disputed papers ${ }^{1-4}$ in the 1990s. Zhang says that the notes and samples accidentally sank in Tianjin Bay in a shipping container when he was moving back to China in 2003. Zhang, now at the Beijing University of Aeronautics and Astronautics, says that he stands by the work.

\section{FURTHER CHALLENGES}

Various faculty members at Tohoku University have since challenged both the university's decision not to investigate further and the composition of the initial investigating committee. The conflict has come to focus more on how the university should handle such allegations than on the papers themselves.

In a letter sent to the university's researchaffairs committee in February 2008, economics professor Izumi Omura, writing with four other university faculty members, pointed out that the five-person investigating committee did not feature a metallic-glass specialist, and that the specialist brought in to review the technical aspects of the report and "to ensure objectivity" had previously co-authored other papers with Inoue. "That was ludicrous," says Omura.

Shoji, the committee head, defends his decision. "In picking the independent expert, I don't think you necessarily decide based on external appearances," he says. "Quality is what's important."
Omura and other critics also point out, however, that the committee included three people (Shoji, Makoto Watanabe and Keiichi Noe) who had been promoted to their current positions as executive vice-presidents by Inoue since he became university president in 2006. Inoue denies any influence over the committee's make-up. Shoji says that he and other committee members discussed the problem of conflict of interest but decided they would "be able to fairly evaluate the situation". Some critics believe that actual fairness is not enough, and that such a committee must also be seen to

"We see the
president as
just another
scientist and so
we leave it up to
the university
to do any
investigation."
be free of any potential conflicts of interest.

In April 2008, university officials rebuffed Omura's letter, defending both the committee's operations and its conclusions.

But in July 2008, 11 researchers from Tohoku's Institute of Multidisciplinary Research for Advanced Materials sent a petition to the university calling for further explanation of the investigating committee's initial report. Attached to the petition was a covering letter by the institute's director, Fumio Saito (who had not signed the petition himself). Then, just over a month later, Saito sent a letter to all university divisions apologizing for implying in his covering letter that the petition expressed "the collective opinion of the institute". Saito's apology added to the controversy.

In yet another twist, in April 2009 a university committee chaired by Inoue temporarily postponed the granting of emeritus status to two retiring faculty members who had been involved with Omura on a website that collects information about the dispute. Emeritus status is customarily granted to retiring professors who have been at the university for at least seven years, as both had been. According to Yukihisa Kitamura, an executive vicepresident at Tohoku University, it was a "rare" measure taken while the two were under investigation for allegedly "dishonouring the university" by being involved with the website. In June, with the investigation still under way, the university granted the two emeritus status.

The unrest looks set to continue. During April and May last year, three key science-funding agencies - the science and education ministry, the Science and Technology Agency and the New Energy and Industrial Technology Development Organization - all asked Tohoku University to evaluate accusations raised by Omura and three others. Citing confidentiality rules, a lawyer representing Inoue and Tohoku University declined to say what actions the university would take in response to the requests. Zhang has not responded to Nature's request for further comment.

Inoue has recognized some points raised by critics. In January last year, he published errata $^{14}$ on two of the papers ${ }^{2,3}$ in dispute. In an accompanying explanation ${ }^{15}$, Inoue and his co-authors "apologize that these papers did not spell out all the experimental details as precise [sic] as we should have". But with the critics and the university at an apparent stalemate, the groups will probably be left to fight it out among themselves. In June 2010, Inoue sued Omura and others for defamation based on allegations posted on their website. In August, Omura's group countersued, claiming that Inoue was unjustly suing and trying to restrict their right to challenge research, and claiming defamation based on certain documents released by Inoue when initiating his lawsuit. The cases are pending.

Japan has no external body, akin to the US Office of Research Integrity, for investigating alleged scientific misconduct, despite calls for one from some quarters ${ }^{16}$. Only the minister of education has authority over a university president, and Kosaku Okada, a representative from the ministry's division familiar with the case, says that the ministry will not get involved. "We see the president as just another scientist and so we leave it up to the university to do any investigation," he says. But an independent investigation may be the only way to silence the critics.
1. Mater Trans. 34, 1234-1237 (1993).
2. Mater. Trans. 36, 1184-1187 (1995).
3. Mater. Trans. 37, 185-187 (1996)
4. Mater. Trans. 39, 1001-1006 (1998).
5. Scripta Mater. 54, 321-326 (2006).
6. Nature Mater. 8, 887-891 (2009).
7. Acta Mater. 57, 1290-1299 (2009)
8. Acta Mater. 54, 2975-2982 (2006).
9. J. Non-Cryst. Solids 351, 2519-2523 (2005).
10.Mater. Trans. 38, 473-477 (1997).
11. Mater. Trans. 48, 3190-3192 (2007)
12. Mater. Trans. 50, 2502-2503 (2009).
13.Mater. Trans. 50, 2504-2506 (2009).
14.Mater. Trans. 51, 196a (2010).
15.Mater. Trans. 51, 196b (2010).
16. Nature 439, 514 (2006).

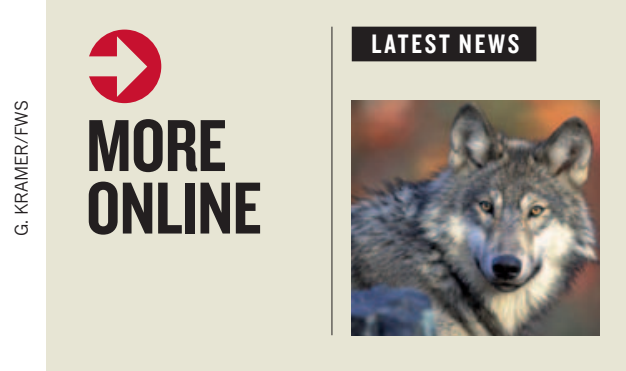

\begin{tabular}{l|l} 
US states & - Connect the quantum dots for a \\
striving to cull & full-colour image go.nature.com/oznnkt \\
grey wolves & - Genetic engineering brings cloned \\
could sidestep & crops closer go.nature.com/3tonw1 \\
science & - Laser in reverse go.nature.com/sloyse \\
go.nature. & - Bone hormone affects male fertility \\
com/4zmmic & go.nature.com/sqd47e
\end{tabular}

\section{MORE STORIES}

Connect the quantum dots for a full-colour image go.nature.com/oznnkt - Genetic engineering brings cloned crops closer go.nature.com/3tonw1 - Laser in reverse go.nature.com/sloyse go.nature.com/sqd47e

\section{Q\&A}

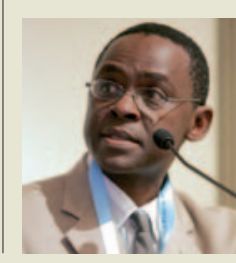

Incoming director of developing-world science academy talks about brain drain go.nature.com/ ifhhlbs 